\title{
A Herbal Formula HT051, a Combination of Pueraria lobata and Rehmannia glutinosa, Prevents Postmenopausal Obesity in Ovariectomized Rats
}

\author{
Yoon Hee Lee, ${ }^{1}$ Bora Jin, ${ }^{1}$ Sunghyun Lee, ${ }^{1}$ Jin-Young $0{ }^{1},{ }^{1}$ Jungbin Song, ${ }^{2}$ \\ Donghun Lee, ${ }^{2}$ Young-Sik Kim, ${ }^{2}$ and Hocheol Kim ${ }^{2}$ \\ ${ }^{1}$ Korea Institute of Science and Technology for Eastern Medicine (KISTEM), NeuMed Inc., Seoul 130-701, Republic of Korea \\ ${ }^{2}$ Department of Herbal Pharmacology, College of Korean Medicine, Kyung Hee University, Seoul 130-701, Republic of Korea \\ Correspondence should be addressed to Hocheol Kim; hckim@khu.ac.kr
}

Received 15 September 2017; Revised 24 November 2017; Accepted 4 December 2017; Published 26 December 2017

Academic Editor: Shao-Hsuan Kao

Copyright @ 2017 Yoon Hee Lee et al. This is an open access article distributed under the Creative Commons Attribution License, which permits unrestricted use, distribution, and reproduction in any medium, provided the original work is properly cited.

\begin{abstract}
Menopause is strongly associated with an increased risk of metabolic dysfunctions due to the decline in estrogen. Here, we hypothesized that dietary HT051, containing the roots of Pueraria lobata and Rehmannia glutinosa, has beneficial effects on ovariectomized $(\mathrm{OVX})$ rats by regulating lipid metabolism. Forty-eight female Sprague-Dawley rats were randomly divided into 4 groups: sham-operated (Sham), OVX, OVX with low-dose HT051 supplementation, and OVX with high-dose HT051 supplementation. The rats were fed with a modified AIN-93G diet or an HT051-containing modified AIN-93G diet for 8 weeks. Body weight, fat mass, and serum levels of total cholesterol, triglyceride, glucose, alanine transaminase, and aspartate transaminase decreased in HT051-fed OVX rats. Dietary HT051 supplementation significantly decreased the mRNA expression of lipogenesisrelated genes, including sterol regulatory element-binding protein $1 \mathrm{c}$ and fatty acid synthase, and increased the mRNA expression of $\beta$-oxidation-related genes, including peroxisome proliferator-activated receptor and carnitine palmitoyl transferase 1 in the liver of OVX rats. Moreover, the expression of genes involved in adipogenesis and inflammation was significantly lower in the adipose tissue of OVX rats fed with HT051 than in the OVX group. These findings suggest that HT051 may be a potential natural alternative for the management of postmenopausal metabolic dysfunctions.
\end{abstract}

\section{Introduction}

Menopause is a biological stage in a woman's life when menstrual cycles cease resulting from the loss of ovarian function and estrogen deprivation [1,2]. Although some women undergo early menopause due to the surgical removal of ovaries, or through radiation or chemotherapy, generally menopause is an event that occurs as a result of ageing, and most women experience menopause within the range of 40 and 58 years of age [3]. Postmenopause is defined as the time of the final menstrual period, followed by one year after the last period.

Postmenopause is strongly associated with an increased risk of obesity owing to estrogen level depletion [4]. Estrogen regulates insulin sensitivity of the pancreas, liver, and skeletal muscle and suppresses fat distribution, differentiation, and fibrosis of white adipose tissue (WAT) and induces thermogenesis of brown adipose tissue (BAT), thus impacting lipid metabolism [5]. Thus, estrogen deprivation strongly affects adipocyte differentiation and brings about a redistribution of fat, leading to increased visceral fat stores [6]. Postmenopausal women have greater amounts of the visceral body fat compared with premenopausal women. Increased visceral fat is strongly associated with insulin resistance and inflammation, which are key factors for developing metabolic dysfunctions, including type 2 diabetes mellitus, cardiovascular disease, and nonalcohol fatty liver disease (NAFLD) $[6,7]$. Moreover, higher abdominal adiposity, particularly subcutaneous adiposity, is a key risk factor of vasomotor symptoms (VMS) for early postmenopause [8]. VMS are the most common initial menopause symptom, often called "hot flashes," and are characterized by a sudden intense heat, often 
to the face, neck, and chest, and spread throughout the body. VMS disturb the quality of life by affecting sleep, mood, and cognitive function [9]. Therefore, the management and prevention of postmenopausal obesity are extremely important for maintaining health and improving quality of life in the postmenopausal populace.

Hormone replacement therapy (HRT) is the strategy currently used for preventing and treating the symptoms of postmenopause [10]. Ironically, long term HRT has been associated with increased risk of undesired side effects including headache, fluid retention, swollen breasts, breast cancer, endometrial cancer, venous thromboembolism, and cardiovascular disease $[11,12]$. In other words, there are no treatments that can be used safely in the long term in the management of postmenopausal syndromes. Thus, it is necessary to develop a new drug of natural or synthetic origin, with minimal side effects.

Many natural products have been used in clinical practice to enhance the health of postmenopausal women. For improving postmenopausal syndrome, we selected two herbs, the roots of Pueraria montana var. lobata (Willd.) Sanjappa \& Pradeep (Leguminosae) and Rehmannia glutinosa (Gaertn.) DC. (Plantaginaceae), and designated the resulting formula as HT051. P. lobata, also known as Galgeun, has been traditionally used for reducing dry mouth, promoting circulation, increasing the blood flow, and treating alcoholism, cardiovascular disease, and type 2 diabetes mellitus [13]. Recent studies have demonstrated that $P$. lobata improves glucose tolerance in $o b / o b$ mice, reduces body weight gain and serum lipid levels in obese mice, inhibits skeletal muscle atrophy in obese mice, and prevents bone loss in ovariectomized (OVX) mice $[14,15]$. P. lobata contains a high content of isoflavonoids, especially puerarin, daidzin, daidzein, and genistein [16]. Isoflavonoids are a type of phytoestrogen that can produce an estrogen-like effect, used as a natural alternative to HRT to improve menopausal symptoms [17]. R. glutinosa, also known as Jihwang, has been widely used as traditional Chinese and Korean medicine for improving the circulatory system, cardiovascular system, nervous system, immune system, and bone metabolism [18].

A combination of P. lobata and R. glutinosa has been reported to prevent osteoporosis, reduce body weight, and induce fat oxidation of skeletal muscle in an OVX animal model [19-21]. A recent study has demonstrated that the combination of $P$. lobata and $R$. glutinosa extracts shows an antiosteoporosis effect by inhibiting the expression of receptor activator of nuclear factor kappa-B ligand (RANKL), which induces osteoclast activation and bone resorption in the OVX animal model [19]. Supplementation of a mixture of $P$. lobata and $R$. glutinosa increased fat oxidation through the upregulation of plasma membrane-bound fatty acid binding protein (FABPpm) in skeletal muscle [20]. Moreover, a combination of $P$. lobata and R. glutinosa extracts decreased body weight, retroperitoneal fat, and perirenal fat [21]. However, the mechanism underlying the antiobesity activity of a combination of $P$. lobata and $R$. glutinosa extracts has not been studied yet. The aim of this study was to investigate the antiobesity effect of HT051, a P. lobata and R. glutinosa mixture, and its mechanisms in OVX rats. In the present study, we examined body weight, WAT weight, serum lipid levels, and the expression of genes involved in adipogenesis, lipogenesis, $\beta$-oxidation, and inflammation in the liver and WAT of OVX rats to elucidate potential underlying mechanisms of HT051.

\section{Materials and Methods}

2.1. Plant Material. The dried roots of P. lobata and R. glutinosa were purchased from Dongkyung Co. (Seoul, Republic of Korea). They were identified by Professor Dr. Hocheol Kim, and the voucher specimens (\#HP028 and \#HP130) were deposited at the Department of Herbal Pharmacology, College of Korean Medicine, Kyung Hee University (Seoul, Republic of Korea).

2.2. Sample Preparation and High Performance Liquid Chromatography (HPLC) Analysis. The dried roots of P. lobata and $R$. glutinosa were extracted separately with water for $4 \mathrm{~h}$ twice at $100^{\circ} \mathrm{C}$ in a reflux apparatus. The extracts were filtered and concentrated under reduced pressure, and samples were spray-dried with $20 \%$ dextrin for R. glutinosa and no dextrin for P. lobata. The extract yield of $R$. glutinosa was $45.6 \%$ and the yield for P. lobata was $29.6 \%$. For the preparation of HT051, P. lobata and R. glutinosa extracts were mixed at a ratio of $2.4: 1$. The quantitative authentication of HT051 was performed by a HPLC analysis system equipped with a Waters 1525 pump, a 2707 autosampler, and a 2998 PDA detector (Waters, Milford, MA, USA). The chromatic separation was achieved at $40^{\circ} \mathrm{C}$ on Waters Sunfire ${ }^{\mathrm{TM}} \mathrm{C} 18$ $(250 \mathrm{~mm} \times 4.6 \mathrm{~mm}$ i.d., $5 \mu \mathrm{m}$ particle size) column. The gradient program to analyze puerarin, which is a representative component of $P$. lobata, was as follows: $0-10 \mathrm{~min}, 12-12 \%$; $10-15 \mathrm{~min}, 12-65 \%$; $15-17 \mathrm{~min}, 65-65 \%$; $17-18 \mathrm{~min}, 65-12 \%$; $18-25 \mathrm{~min}, 12-12 \%$ solvent $\mathrm{B}$. The gradient program to analyze catalpol, a representative component of $R$. glutinosa, was as follows: $0-10 \mathrm{~min}, 2-2 \%$; $10-20 \mathrm{~min}, 2-45 \%$; $20-23 \mathrm{~min}, 45-$ $45 \%$; $23-25 \mathrm{~min}, 45-2 \%$; $25-35 \mathrm{~min}, 2-2 \%$ solvent $\mathrm{B}$. The flow rate was $1 \mathrm{~mL} / \mathrm{min}$ and the injection volume was $10 \mu \mathrm{L}$. The puerarin and catalpol were monitored at $254 \mathrm{~nm}$ and $205 \mathrm{~nm}$, respectively. Each extract was analyzed in triplicate. The content of puerarin and catalpol was calculated for standardization. In HT051, the content of puerarin was $65.27 \pm 1.31 \mathrm{mg} / \mathrm{g}$ and catalpol was $3.21 \pm 0.01 \mathrm{mg} / \mathrm{g}$. A 3D chromatogram of HT051 is shown in Figure 1.

2.3. Animals and Treatments. Female Sprague-Dawley (SD) rats, 8 weeks old (170-190 g), were purchased from Samtako (Osan, Republic of Korea). The animals were housed in polycarbonate cages (3 rats/cage) under controlled temperature $\left(23 \pm 2^{\circ} \mathrm{C}\right)$, relative humidity (55-60\%), and lighting conditions (lights on from 07:00 hours to 19:00 hours) with food and water made available ad libitum. Animal experiments were reviewed and approved by the Institutional Animal Care and Use Committee of Korea Institute of Science and Technology for Eastern Medicine (KISTEM) (project number: KISTEM-IACUC-2016-002; date of approval: 29 April 2016), and the animals were cared for according to the Guidelines for the Institutional Animal Care and Use 

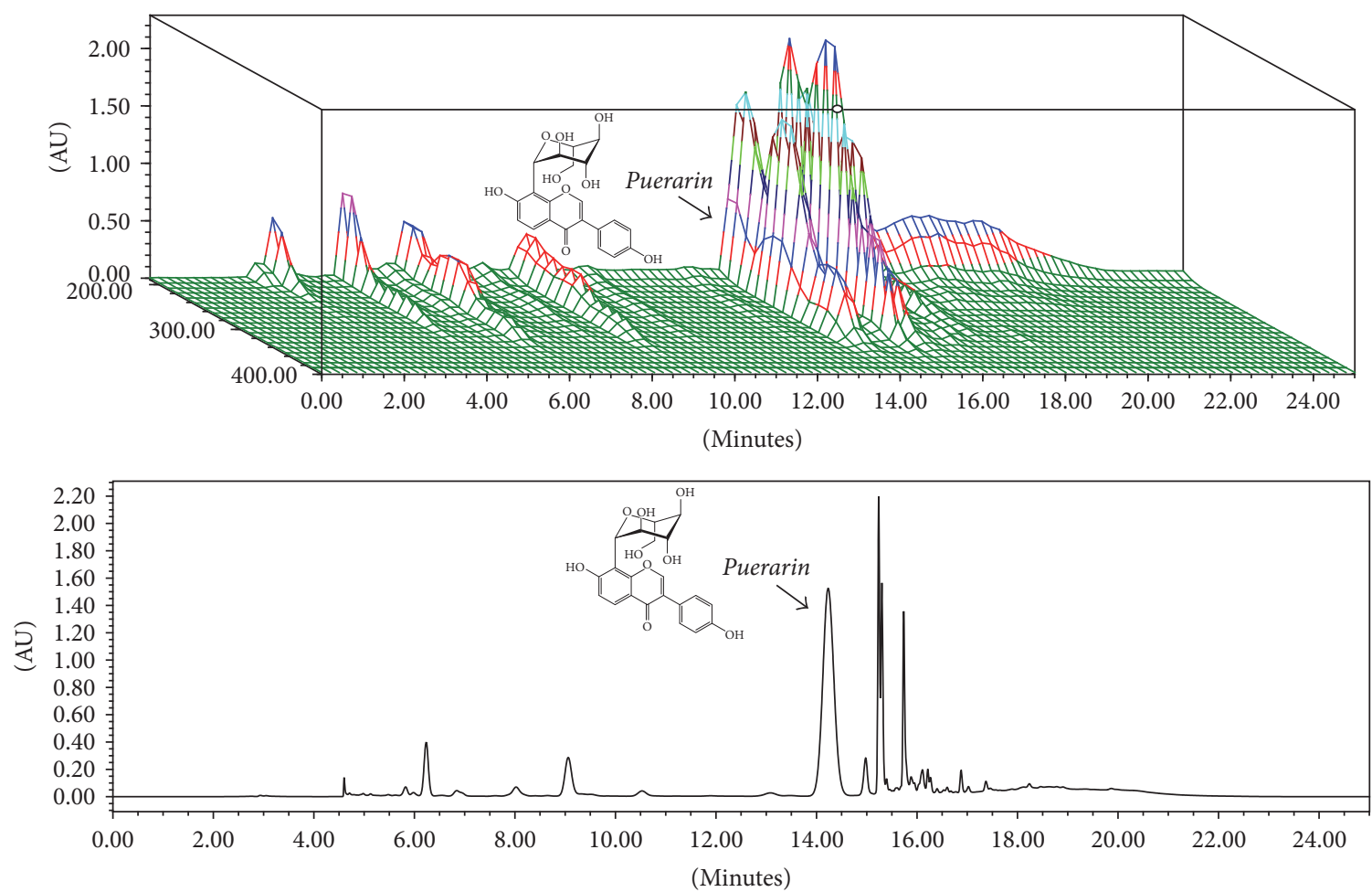

(a)
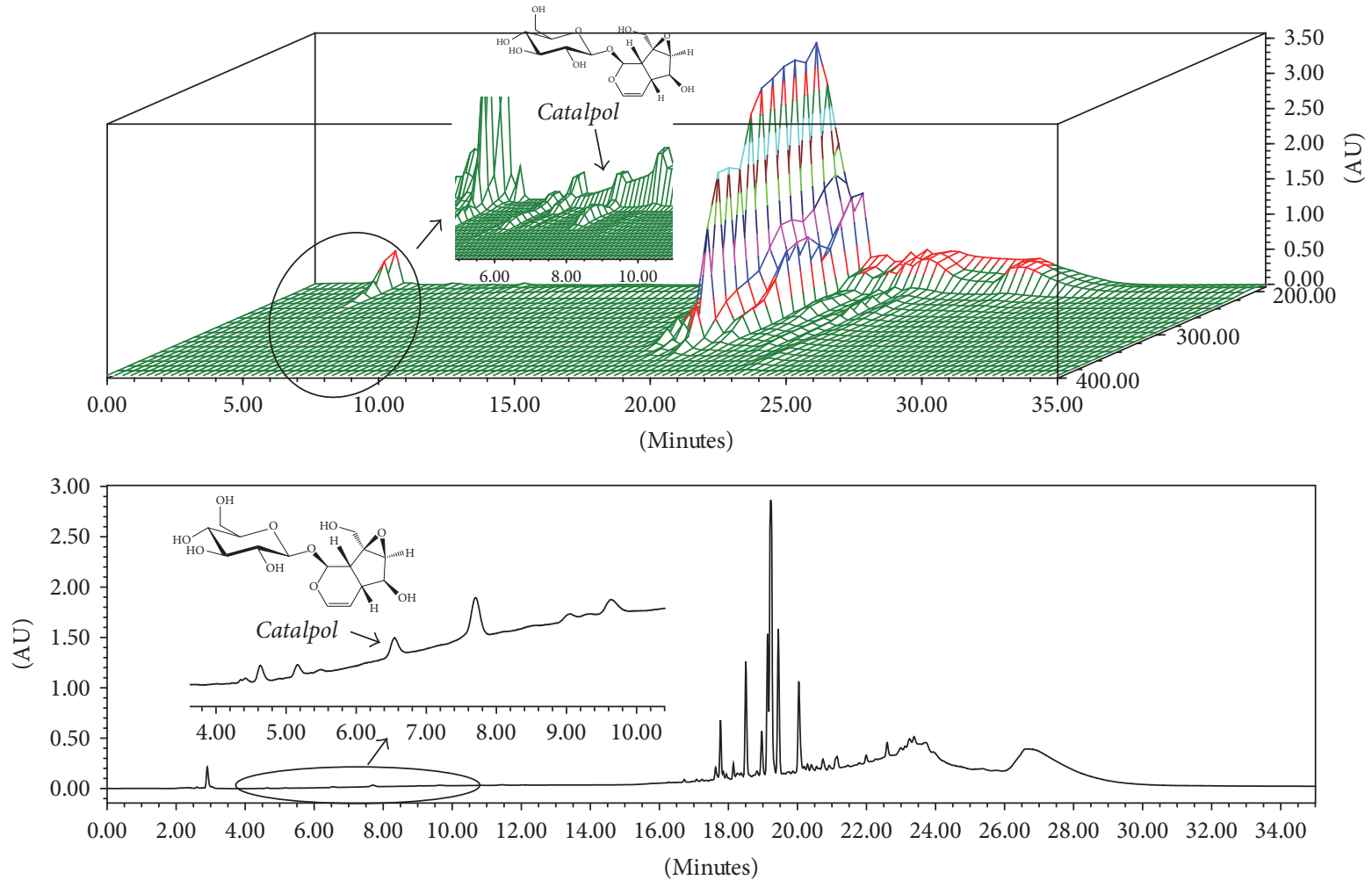

(b)

FIGURE 1: 3D and 2D HPLC chromatograms of HT051, a blend of two herbal extracts: (a) puerarin of P. lobata root; (b) catalpol of R. glutinosa root. 
TABLE 1: Composition of the diets.

\begin{tabular}{lccc}
\hline & Normal diet & OVX + 0.3\% HT051 & OVX + 1.0\% HT051 \\
\hline Casein & 200 & 200 & 200 \\
Cornstarch & 397.486 & 397.486 & 397.486 \\
Dextrin & 132 & 132 & 132 \\
Sucrose & 100 & 100 & 100 \\
Cellulose & 50 & 50 & 50 \\
Corn oil & 70 & 70 & 70 \\
t-Butylhydroquinone & 0.014 & 0.014 & 0.014 \\
Salt mix \#210025 & 35 & 35 & 35 \\
Vitamin mix \#310025 & 10 & 10 & 10 \\
L-Cystein & 3 & 3 & 3 \\
Choline bitartrate & 2.5 & 2.5 & 2.5 \\
HT051 & 0 & 3 & 10 \\
\hline Total (g) & 1000 & 1003 & 1010 \\
\hline
\end{tabular}

Committee of Korea Institute of Science and Technology for KISTEM.

After acclimatization for 1 week, 9-week-old female SD rats were anesthetized with 5\% isoflurane, and ovaries were removed bilaterally. The rats were divided into the four following treatment groups ( $n=12$ per group): Group 1, Sham group that had sham surgery and received a modified AIN-93G diet in which soybean oil was replaced with corn oil (Saeronbio Inc., Uiwang, Republic of Korea); Group 2, CON group that had ovariectomy and received a modified AIN93G diet; Group 3, 1.0\% HT051 group that had ovariectomy and received a modified AIN-93G diet containing $1.0 \%$ HT051; Group 4, 0.3\% HT051 group that had ovariectomy and received a modified AIN-93G diet containing 0.3\% HT051. The composition of the diets is shown in Table 1. All groups were treated for eight weeks. During the experimental period, body weight and food intake were determined weekly.

At the end of the treatment period, the rats were fasted for $12 \mathrm{~h}$, and blood was collected via the abdominal aorta. The rats were anesthetized with $\mathrm{N}_{2} \mathrm{O} / \mathrm{O}_{2}$ gas and isoflurane. The serum samples were prepared by centrifugation of the collected blood samples $\left(1,300 \mathrm{~g}\right.$ for $10 \mathrm{~min}$ at $4^{\circ} \mathrm{C}$ ) and then stored at $-80^{\circ} \mathrm{C}$ for biochemical determinations. Liver, spleen, WAT, and uterus tissue were dissected, washed with saline solution, weighed, and stored at $-80^{\circ} \mathrm{C}$ until further analysis.

2.4. Biochemical Serum Analysis. Serum ALT (98-24010-US), AST (98-24016-US), TC (98-24005-US), glucose (98-24009US), and TG (98-24019-US) concentrations were measured using an autoanalyzer (IDEXX VetTest ${ }^{\circledR}$ Chemistry Analyzer, IDEXX Laboratories, Inc., Westbrook, ME, USA) according to the manufacturer's instructions. The VetTest apparatus requires $70 \mathrm{ul}$ volumes of serum for all parameters. The different biochemical tests are available as dry slides that include all necessary reagents. Serum estradiol level was determined using Enzyme-Linked Immunosorbent Assay (ELISA) kit (ab108667, Abcam, Cambridge, UK) according to the manufacturer's instructions.
2.5. Real-Time Quantitative PCR Analysis. Total RNA from liver and WAT were extracted using Qiazol reagent (Invitrogen Technologies, Waltham, MA, USA). According to the manufacturer's instruction, the total RNA concentration and 260/280 nm ratio were evaluated using an Epoch 2 Microplate Spectrophotometer (BioTek Instruments, Inc., Winooski, VT, USA). Single strand RNA samples were converted to cDNA using the High Capacity cDNA Reverse Transcription Kit (Applied Biosystems, Foster City, CA, USA). The cDNA was performed using the Step-One-Plus RT-PCR System (Applied Biosystems, USA) as follows: after $10 \mathrm{~min}$ at $95^{\circ} \mathrm{C}$, 40 cycles of $15 \mathrm{~s}$ at $95^{\circ} \mathrm{C}$ and $60 \mathrm{~s}$ at $60^{\circ} \mathrm{C}$, followed by the melting curve for $15 \mathrm{~s}$ at $95^{\circ} \mathrm{C}$ for $15 \mathrm{~s}$, a gradual decrease to $60^{\circ} \mathrm{C}$ in the last $60 \mathrm{~s}$, and then a gradual increase to $95^{\circ} \mathrm{C}$ for the last $15 \mathrm{~s}$. Primers were designed using nucleotide sequence and synthesized by Bioneer (Daejeon, Republic of Korea). The relative gene expression was normalized using the housekeeping gene (GAPDH). The sequences of the primers used in this study are listed in Table 2 . The relative fold change of gene expression was calculated using the DeltaDelta method.

2.6. Statistical Analysis. Statistical analysis was performed using SAS 9.3 (SAS Institute Inc., Cary, NC, USA). All data were presented as the mean \pm standard deviation $(\mathrm{SD})$. The effects of different treatments were compared by one-way ANOVA test, followed by the post hoc Duncan's test for multiple comparisons. $p<0.05$ was considered statistically significant.

\section{Results}

3.1. Weekly Body Weight and Weight Gain. The values of weekly body weight, body weight gain, and food intake in OVX rats measured during the 8-week administration of HT051 are shown in Figure 2 and Table 3. The weekly body weight showed a significant difference between Sham and OVX groups from the first week through the entire experimental period $(p=0.0073$, Figure 2(a)). 1.0\% HT051 
TABLE 2: Sequences of primers used for real-time quantitative PCR analysis.

\begin{tabular}{lrc}
\hline Gene & Forward primer $\left(5^{\prime}-3^{\prime}\right)$ & Reverse primer $\left(5^{\prime}-3^{\prime}\right)$ \\
\hline GAPDH & TGGCCTCCAAGGAGTAAGAAAC & CAGCAACTGAGGGCCTCTCT \\
SREBP1c & AAAACCAGCCTCCCCAGAGC & CCAGTCCCCATCCACGAAGA \\
FAS & GCTAATGCCTACCTGAGTCACAC \\
PPAR $\alpha$ & TGGAGTCCACGCATGTGAAG & GACAACTTAGTCTGCTGCTCTCTG \\
CPT-1 & TAGGACAGGCAGAAAATTGC & CGCCAGCTTTAGCCGAATAG \\
PPAR $\gamma$ & CCCTGGCAAAGCATTTGTAT & CAGTAGGAGCCGATTCAAAA \\
aP2 & GGCTTCGCCACCAGGAA & GGTGATTTGTCTGTTGTCTTTCC \\
MCP-1 & AATGAGTCGGCTGGAGAACTAC & CCCTTCTACGCTGATGATCAAGT \\
IL-6 & CAGACCTAATGCAGAGAAGTAGCC & GATCTCTCTCTTGAGCTTGGTGAC \\
TNF- $\alpha$ & GGCAGGTCTACTTTGGAGTCAT & GAGCCATCAGTCCTCCATATCTAC \\
& & GAGTAGACGATAAAGGGGTCAGAG \\
\hline
\end{tabular}

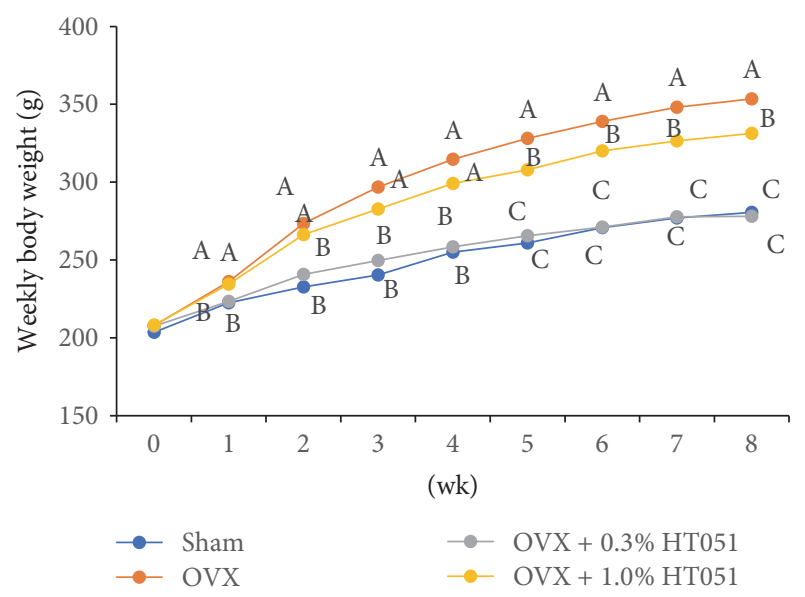

(a)

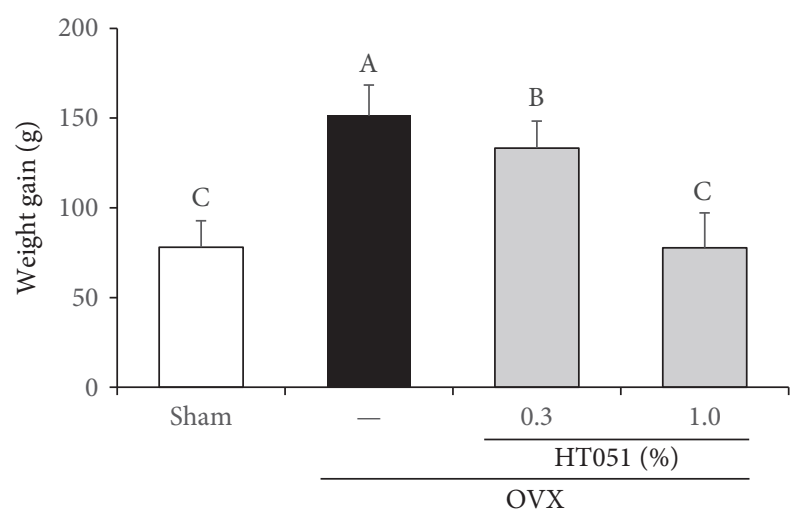

(b)

FIGURE 2: Effects of HT051 on weekly body weight (a) and weight gain (b) in ovariectomized rats. Each value is the mean $\pm \mathrm{SD}(n=12$ per group). Data were analyzed by one-way analysis of variance (ANOVA) followed by Duncan's multiple range test. Values not sharing the same letters are significantly different among the groups at $p<0.05$.

supplementation also significantly reduced weekly body weight from week 1 compared to that in the OVX group until the end of the experiment. Furthermore, the weekly body weight of the $0.3 \%$ HT051 group was significantly different from week 5 compared to that of the OVX group until the end
TABLE 3: Food intake.

\begin{tabular}{lcccc}
\hline & Sham & OVX & OVX + & OVX + 1.0\% \\
& & & $0.3 \%$ HT051 & HT051 \\
\hline $\begin{array}{l}\text { Food intake } \\
\text { (g/day) }\end{array}$ & $15.49 \pm 1.43$ & $16.43 \pm 1.11$ & $15.72 \pm 1.34$ & $16.25 \pm 1.19$ \\
\hline
\end{tabular}

of the experimental period ( $p<0.0001$ ). The body weight gain showed a significant difference between the OVX group and the other groups $(p<0.0001$, Figure 2(b)).

3.2. Organ Weights. Table 4 shows the weight of the liver, spleen, and WAT (total WAT, mesenteric, abdominal, gonadal, and perirenal fat). As shown in Table 4, the weight of the liver and total WAT of the OVX group was significantly higher than those of the Sham group after the feeding period. HT051 supplementation decreased the weight of the liver and total WAT compared to that in the OVX group ( $p=$ 0.0134 and $p<0.0001$, resp.). A significant difference was found in the total fat weight including mesenteric, abdominal, gonadal, and perirenal fat between the OVX group and HT051 groups $(p<0.0001, p<0.0001, p<0.0001$, and $p<0.0001$, resp.). In the HT051-supplemented groups, all WAT weights were decreased dose-dependently compared to the OVX group. There was no difference in the weight of the spleen among groups.

3.3. Uterus Weight and 17 $\beta$-Estradiol Contents in Serum. Ovariectomy resulted in a significant reduction in uterus weight in the ovariectomized rats, and there was no uterus hypertrophy in HT051-supplemented groups $(p<0.0001$, Figure 3(a)). Serum $17 \beta$-estradiol levels were significantly lower in OVX rats compared to that in the Sham group $(p=0.0064)$. However, there was no significant difference in $17 \beta$-estradiol level between the OVX group and two OVX + HT051 groups (Figure 3(b)).

3.4. Biochemical Analysis of Serum. Serum levels of triglyceride (TG) and total cholesterol (TC) were significantly higher in the OVX group compared with the Sham group ( $p<0.0001$ and $p=0.0001$, resp.). Blood lipid levels were significantly lower in two OVX + HT051 groups (Figure 4(a)). The level of fasting glucose in the OVX group was also 
TABLE 4: Effects of 8-week administration of HT051 on organ weight in OVX rats.

\begin{tabular}{lcccc}
\hline Weight $(\mathrm{g})$ & Sham & OVX & OVX +0.3\% HT051 & OVX + 1.0\% HT051 \\
\hline Liver & $6.37 \pm 0.61^{\mathrm{b}}$ & $6.98 \pm 0.50^{\mathrm{a}}$ & $6.03 \pm 0.71^{\mathrm{b}}$ & $6.35 \pm 0.84^{\mathrm{b}}$ \\
Spleen & $0.56 \pm 0.12$ & $0.66 \pm 0.12$ & $0.64 \pm 0.14$ & $0.62 \pm 0.10$ \\
Total WAT & $15.83 \pm 4.27^{\mathrm{c}}$ & $33.17 \pm 8.81^{\mathrm{a}}$ & $26.89 \pm 4.62^{\mathrm{b}}$ & $11.83 \pm 2.71^{\mathrm{c}}$ \\
Mesenteric fat & $3.70 \pm 1.13^{\mathrm{c}}$ & $9.39 \pm 2.76^{\mathrm{a}}$ & $7.00 \pm 2.02^{\mathrm{b}}$ & $3.54 \pm 1.94^{\mathrm{c}}$ \\
Abdominal fat & $3.37 \pm 1.28^{\mathrm{c}}$ & $6.58 \pm 1.69^{\mathrm{a}}$ & $4.67 \pm 1.25^{\mathrm{b}}$ & $2.57 \pm 0.91^{\mathrm{c}}$ \\
Gonadal fat & $4.40 \pm 1.76^{\mathrm{b}}$ & $7.89 \pm 2.99^{\mathrm{a}}$ & $7.14 \pm 1.72^{\mathrm{a}}$ & $2.92 \pm 1.12^{\mathrm{b}}$ \\
Perirenal fat & $4.36 \pm 1.32^{\mathrm{b}}$ & $9.32 \pm 2.37^{\mathrm{a}}$ & $8.08 \pm 2.39^{\mathrm{a}}$ & $2.79 \pm 0.88^{\mathrm{b}}$ \\
\hline
\end{tabular}

Each value is the mean $\pm \mathrm{SD}(n=12$ per group) values. Data were analyzed by one-way analysis of variance (ANOVA) followed by Duncan's multiple range test. Values not sharing the same letters are significantly different among the groups at $p<0.05$.

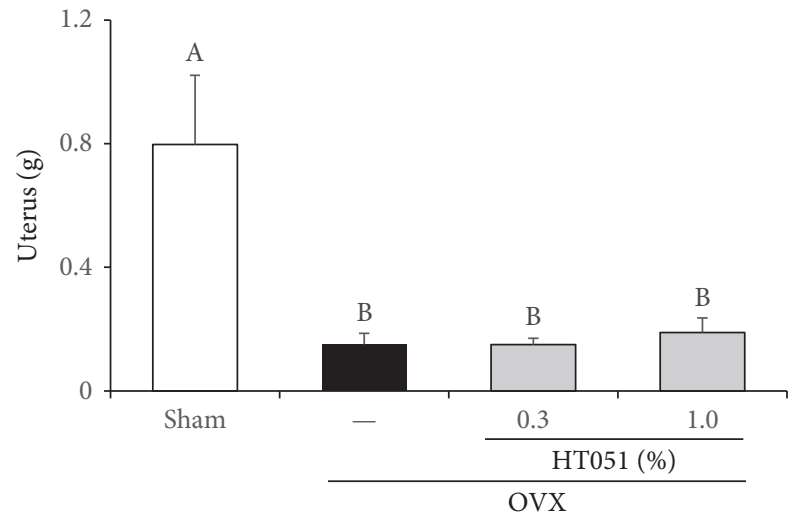

(a)

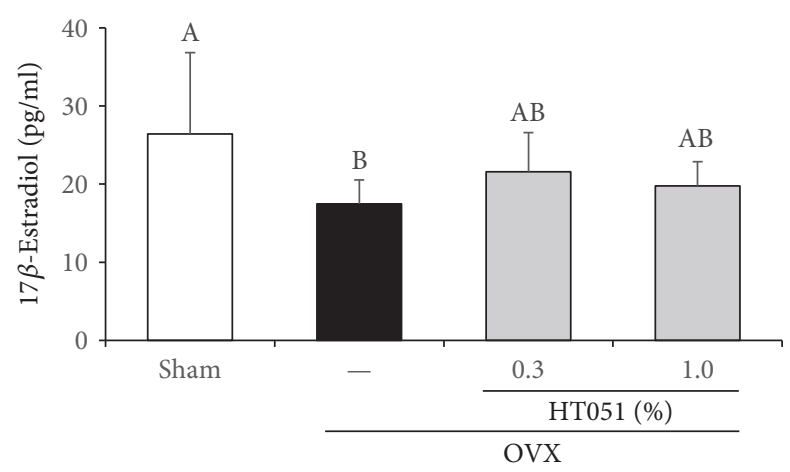

(b)

FIGURE 3: Effects of HT051 on uterus weight (a) and serum $17 \beta$ estradiol level (b) in ovariectomized rats. Each value is the mean \pm $\mathrm{SD}(n=12$ per group). Data were analyzed by one-way analysis of variance (ANOVA) followed by Duncan's multiple range test. Values not sharing the same letters are significantly different among the groups at $p<0.05$.

significantly higher than that in the Sham group. As expected, fasting glucose level was significantly lower in two OVX + HT051 groups that that in the OVX group after 8 weeks $(p<$ 0.0001 , Figure $4(\mathrm{~b})$ ). In addition, alanine transaminase (ALT) levels were significantly lower in two OVX + HT051 groups compared to that in the OVX group $(p<0.0001)$. Serum aspartate transaminase (AST) levels of two OVX + HT051 groups were lower than that of the OVX group, but there was no significant difference (Figure 4(c)).
3.5. Lipogenesis- and $\beta$-Oxidation-Related Gene Expression in the Liver. To confirm the effect of HT051 on lipid metabolism changed by ovariectomy, we measured the transcriptional expression level of lipogenesis- and $\beta$-oxidation-related genes. As shown in Figure 5(a), expression of lipogenesisrelated genes, sterol regulatory element-binding protein $1 \mathrm{c}$ (SREBP-1c), and fatty acid synthase (FAS) was significantly lower in the $1.0 \%$ HT051 group compared to that in the OVX group $(p<0.0014$ and $p<0.0001$, resp.). Furthermore, the expression level of two $\beta$-oxidation-related genes, carnitine palmitoyl transferase 1 (CPT-1) and peroxisome proliferatoractivated receptor $\alpha(\operatorname{PPAR} \alpha)$, was significantly higher in HT051-supplemented groups compared to that in the OVX group ( $p<0.0001$ and $p<0.0001$, resp., Figure 5(b)). However, there was no significant difference between the Sham and OVX groups regarding $\beta$-oxidation-related genes.

3.6. Adipogenesis- and Inflammation-Related Gene Expression in WAT. To evaluate the effects of HT051 on adipocyte differentiation and fat accumulation in menopause-induced rats by ovariectomy, the mRNA expression level of peroxisome proliferator-activated receptor $\gamma(\operatorname{PPAR} \gamma)$ and adipocyte protein 2 (aP2) in WAT was measured (Figure 6(a)). The expression of PPAR $\gamma$ and aP2 mRNA was significantly higher in the OVX group compared with the Sham group $(p<$ 0.0001 and $p<0.0001$, resp.). PPAR $\gamma$ and aP2 mRNA expression was significantly lower in two OVX + HT051 groups compared with the OVX group. In addition, the expression of inflammatory genes including monocyte chemoattractant protein-1 (MCP-1), interleukin-6 (IL-6), and tumor necrosis factor $\alpha(\mathrm{TNF}-\alpha)$ in WAT is shown in Figure 6(b). The OVX group showed the highest levels of expression of WAT inflammatory genes. The level of expression of MCP-1 and IL-6 was significantly lower in two OVX + HT051 groups compared with the OVX group $(p<0.0001$ and $p=$ 0.0083 , resp.). The TNF- $\alpha$ mRNA expression was lower in the OVX + HT051 group than the OVX group, but there was no significant difference.

\section{Discussion}

In this study, we chose the HT051 supplementation of $0.3-1.0 \%$ of the diet. The dose of HT051 consumed by the rats is equivalent to $3.36-11.52 \mathrm{~g}$ of $P$. lobata and $0.7-2.4 \mathrm{~g}$ 


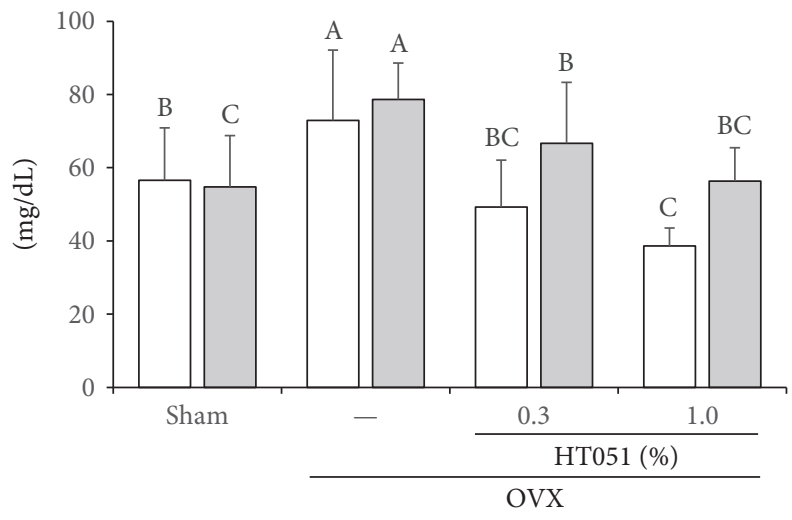

口 TG

TC

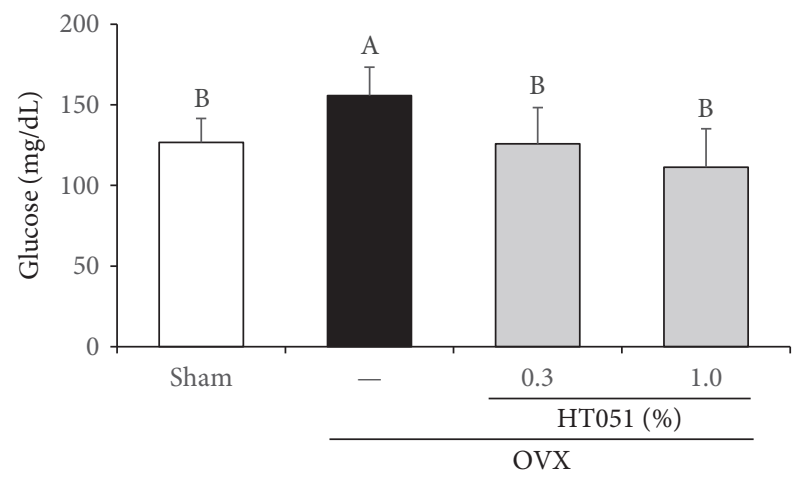

(b)

(a)

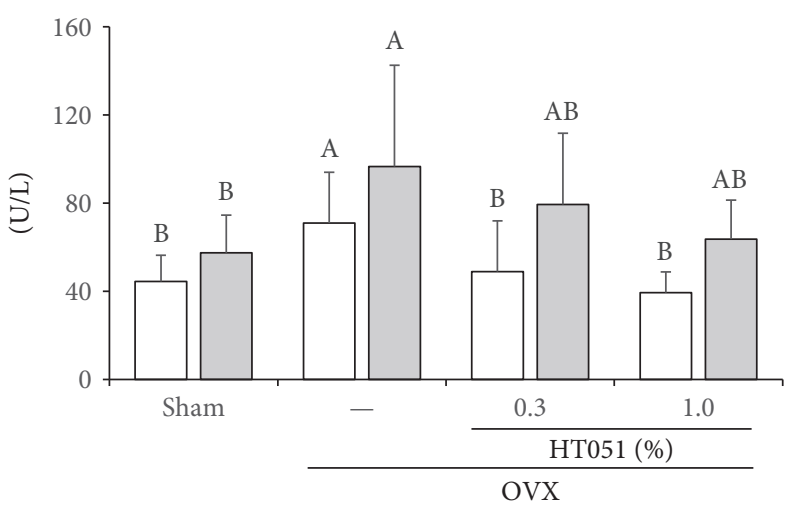

口 ALT

AST

(c)

FIGURE 4: Effects of HT051 on serum lipid (a), fasting glucose (b), and ALT and AST (c) in ovariectomized rats. Each value is the mean \pm $\mathrm{SD}(n=12$ per group). Data were analyzed by one-way analysis of variance (ANOVA) followed by Duncan's multiple range test. Values not sharing the same letters are significantly different among the groups at $p<0.05$.

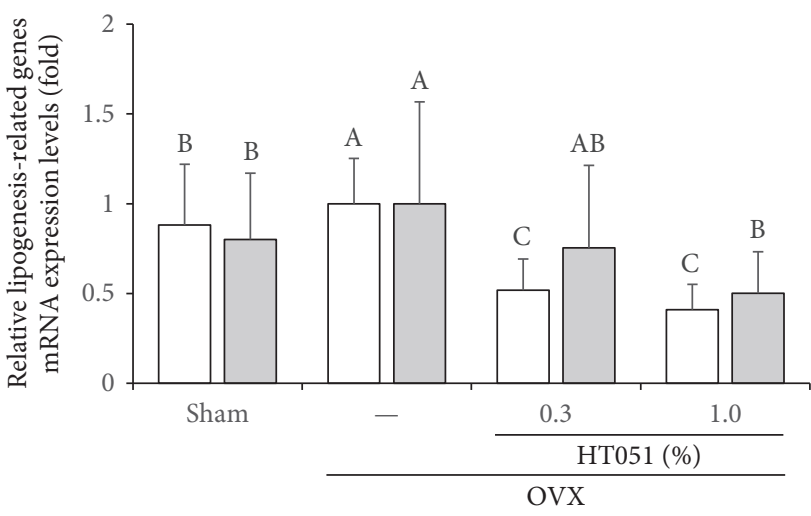

$\square$ SREBP1C

$\square$ FAS

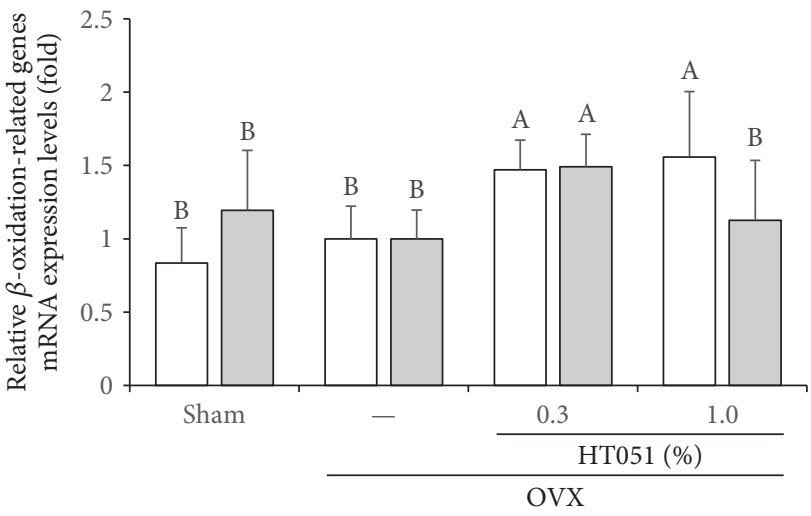

$\square \operatorname{PPAR} \alpha$

CPT-1

(a)

(b)

FIGURE 5: Effects of HT051 on mRNA expression of genes related to hepatic lipogenesis (a) and $\beta$-oxidation (b) in ovariectomized rats. Each value is the mean \pm SD ( $n=12$ per group). Data were analyzed by one-way analysis of variance (ANOVA) followed by Duncan's multiple range test. Values not sharing the same letters are significantly different among the groups at $p<0.05$. 


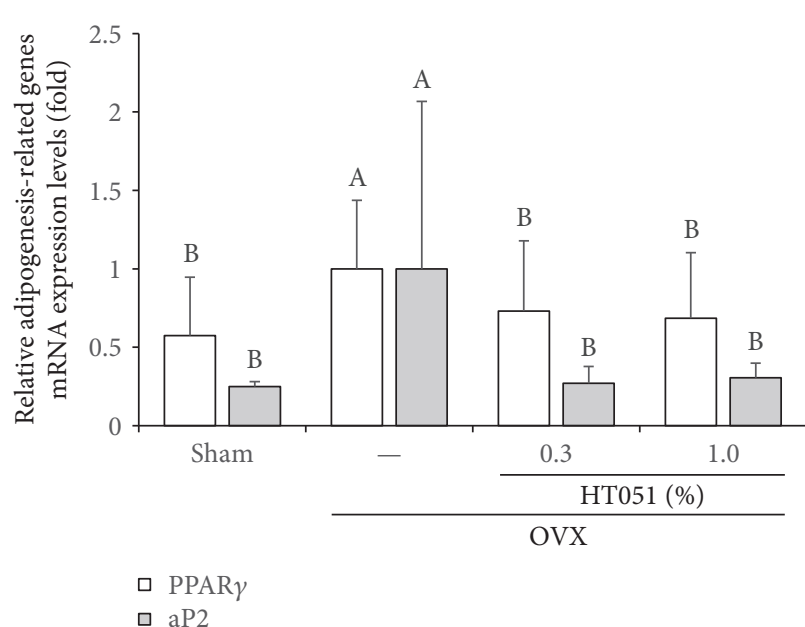

(a)

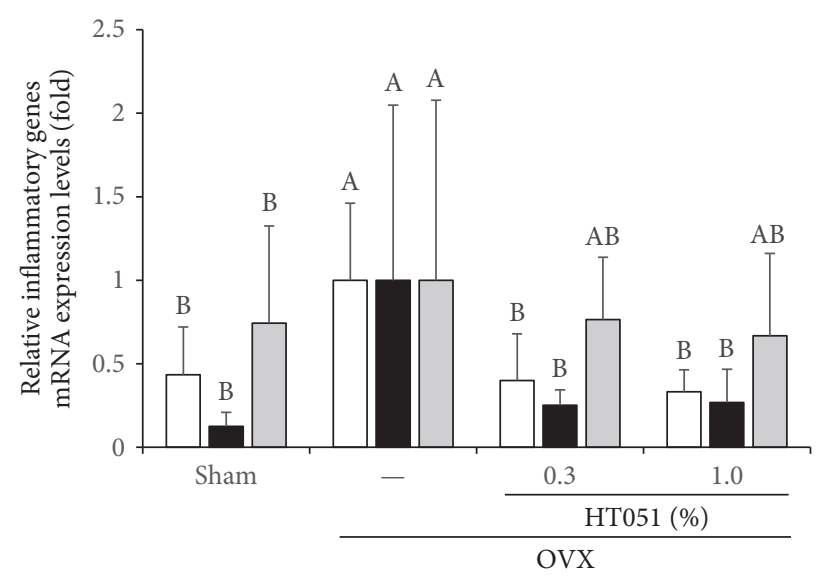

$$
\begin{aligned}
& \text { ․ MCP-1 } \\
& \text { - IL-6 } \\
& \text { TNF- } \alpha
\end{aligned}
$$

FigURE 6: Effects of HT051 on mRNA expression of genes related to WAT adipogenesis (a) and inflammation (b) in ovariectomized rats. Each value is the mean $\pm \mathrm{SD}$ ( $n=12$ per group). Data were analyzed by one-way analysis of variance (ANOVA) followed by Duncan's multiple range test. Values not sharing the same letters are significantly different among the groups at $p<0.05$.

of R. glutinosa in human dose based on the weight of dried roots, respectively. P. lobata and $R$. glutinosa have been used in traditional Korean medicine for a long time and the widely used dose for man in traditional Korean medicine is $12-30 \mathrm{~g} /$ day for $P$. lobata and $10-30 \mathrm{~g}$ for $R$. glutinosa. Since the dose used in this experiment does not exceed the amount of that traditionally used, the dose is not a problem for human supplementation. HT051 reduced body weight, adipose fat mass, and serum lipid and glucose levels in OVX rats. Moreover, HT051 upregulated the expression of enzymes involved in $\beta$-oxidation and downregulated the expression of genes involved in lipogenesis, adipogenesis, and inflammation in liver and adipose tissue of OVX rats.

The uterus weight and serum $17 \beta$-estradiol concentration in the OVX groups decreased compared to those in the Sham group, confirming that ovariectomy successfully induces surgical menopause. Estrogen deprivation in postmenopausal women promotes metabolic syndrome such as obesity, insulin resistance, hyperglycemia, and dyslipidemia [4]. OVX operation results in estrogen deficiency and loss of ovarian function, which is generally accompanied by increased body weight in the form of excessive fat accumulation in human and animals [22]. Actually, OVX model has been used for not only osteoporosis in menopause, but also obesity in menopause $[23,24]$. In our experiments, body and body fat weight dramatically increased in OVX rats and significantly decreased in OVX rats fed dietary HT051, without affecting uterus weight or serum estrogen concentration. These results suggest that HT051 might have antiobesity effects in postmenopausal women, without the influence of estrogen.

Dietary HT051 supplementation significantly reduced the serum lipid and glucose in OVX rats. Total body fat weight is strongly associated with serum lipid and glucose concentration, because excess adipocytes alter glucose and lipid homeostasis $[25,26]$. Excess fat accumulation releases free fatty acids (FFA), one of the adipose tissue-derived factors, and the enhanced FFA leads to increased serum TG and TC [27]. Moreover, increased FFA could lead to elevation of glucose by stimulating hepatic gluconeogenesis [28]. These results suggest that HT051 supplementation might prevent hyperlipidemia and hyperglycemia in postmenopausal obesity.

Liver weight and serum AST and ALT levels were significantly higher in the OVX group than in the Sham group, and these biomarkers were significantly lower in OVX rats fed with HT051 supplementation compared to that in OVX rats. Estrogen deprivation by ovariectomy in animals leads to increased fat mass and hepatic steatosis [29]. Hepatic steatosis is characterized by increased liver weight and increased serum ALT and AST concentrations [30,31]. A previous study demonstrated that postmenopausal women have a higher risk of developing NAFLD when compared with premenopausal women because estrogen deprivation causes the accumulation of body fat and hepatic lipid, which can develop and progress NAFLD [32]. Based on our results, HT051 improves hepatic fat accumulation and may help to prevent NAFLD in postmenopausal women.

Dietary HT051 supplementation inhibited the expression of lipogenic genes, including SREBP1c and FAS, and induced the expression of fatty acid oxidation genes, including PPAR $\alpha$ and CPT-1, in OVX rats. Hepatic lipid metabolism seems to be regulated by changes in the expression of genes related to lipogenesis and fat $\beta$-oxidation [33]. SREBP1c, a transcription factor that targets important lipogenic genes, stimulates lipogenesis, the process of fatty acid and TG synthesis, and it increases the expression of lipogenesis-related genes, such as FAS [34]. Fatty acid $\beta$-oxidation is of multiple catabolic 
processes by which fatty acids are broken down by the expression of various genes, such as PPAR $\alpha$ and CPT-1 [35]. $\operatorname{PPAR} \alpha$, in the superfamily of nuclear receptors, upregulates genes involved in cellular fatty acid uptake and transport, such as CPT-1, for fatty acid oxidation [36]. These results demonstrated that HT051 improves postmenopausal obesity by inhibiting lipogenesis and inducing fat oxidation in the liver.

HT051 supplementation significantly suppressed the expression of adipogenic gene PPAR $\gamma$ and aP2 and inflammatory markers, such as IL- 6 and MCP-1 in WAT. Adipocytes are the fat cells that primarily compose WAT, and the main function of adipocytes is to regulate energy balance by storing and mobilizing TG. Adipogenesis is the process by which preadipocytes transformed into differentiated adipocytes, and this process is regulated by transcription factor such as $\operatorname{PPAR} \gamma$. PPAR $\gamma$ is highly expressed in adipocytes and is required for stimulating expression of genes related to adipogenesis, such as aP2 [37]. Fatty acid binding protein 4, called aP2, facilitates the shuttling of fatty acids and is primarily expressed in adipocytes and macrophages. It has been proposed to be a marker of adipogenesis because it is highly expressed during adipocyte differentiation [38]. Previous studies have demonstrated that PPAR $\gamma$ and aP2 play an important role in lipid metabolism, insulin resistance, hyperglycemia, and atherosclerosis [39]. Mature white adipocytes secrete various inflammatory cytokines, such as IL-6, TNF$\alpha$, and MCP-1 [40]. Moreover, estrogen deprivation promotes immune cell infiltration and increased tissue inflammation because estrogen influences immune and inflammatory conditions [41]. Indeed, adipose tissue inflammation is elevated in OVX animals and postmenopausal women [42-44]. It is believed that the increase in proinflammatory cytokines contributes to the development of various chronic diseases, including osteoporosis, atherosclerosis, liver disease, and cancer $[27,45]$. Our results demonstrated that decreased fat mass in OVX HT051-fed rats is strongly associated with the downregulation of adipogenic and proinflammatory genes.

\section{Conclusion}

In summary, dietary HT051 supplementation improves postmenopausal obesity by activating fat oxidation and suppressing lipogenesis, adipogenesis, and inflammation in the liver and WAT. Based on these findings, HT051 may be a promising alternative to HRT for the management of postmenopausal obesity.
Abbreviations
WAT: White adipose tissue
BAT: $\quad$ Brown adipose tissue
NAFLD: Nonalcohol fatty liver disease
VMS: Vasomotor symptoms
HRT: Hormone replacement therapy
OVX: Ovariectomized
RANKL: Nuclear factor kappa-B ligand
FABPpm: Plasma membrane-bound fatty acid binding protein

ANOVA: Analysis of variance

TG: $\quad$ Triglyceride

TC: $\quad$ Total cholesterol

ALT: $\quad$ Alanine transaminase

AST: $\quad$ Aspartate transaminase

SREBP-1c: Sterol regulatory element-binding protein 1c

FAS: $\quad$ Fatty acid synthase

CPT-1: Carnitine palmitoyl transferase 1

PPAR $\alpha$ : Peroxisome proliferator-activated receptor $\alpha$

PPAR $\gamma$ : Peroxisome proliferator-activated receptor $\gamma$

aP2: $\quad$ Adipocyte protein 2

MCP-1: Monocyte chemoattractant protein-1

IL-6: Interleukin-6

TNF- $\alpha$ : Tumor necrosis factor $\alpha$

FFA: $\quad$ Free fatty acids.

\section{Conflicts of Interest}

Yoon Hee Lee, Bora Jin, Sunghyun Lee, and Jin-Young Oh are employees of NeuMed Inc.

\section{Acknowledgments}

This work was supported by the Bio-Synergy Research Project (NRF-2012M3A9C4048795) of the Ministry of Science, ICT and Future Planning through the National Research Foundation.

\section{References}

[1] P. K. Dalal and M. Agarwal, "Postmenopausal syndrome," Indian Journal of Psychiatry, vol. 57, pp. 222-232, 2015.

[2] H. D. Nelson, "Menopause," The Lancet, vol. 371, no. 9614, pp. 760-770, 2008.

[3] X. Zhu, Y. Liew, and Z. L. Liu, "Chinese herbal medicine for menopausal symptoms," The Cochrane Database of Systematic Reviews, vol. 3, Article ID CD009023, 2016.

[4] R. A. Lobo, S. R. Davis, T. J. De Villiers et al., "Prevention of diseases after menopause," Climacteric, vol. 17, no. 5, pp. 540556, 2014.

[5] M. López and M. Tena-Sempere, "Estrogens and the control of energy homeostasis: A brain perspective," Trends in Endocrinology \& Metabolism, vol. 26, no. 8, pp. 411-421, 2015.

[6] F. Lizcano and G. Guzmán, "Estrogen deficiency and the origin of obesity during menopause," BioMed Research International, vol. 2014, Article ID 757461, 11 pages, 2014.

[7] T.-I. Chiang, I.-C. Chang, H.-H. Lee et al., "Amelioration of estrogen deficiency-induced obesity by collagen hydrolysate," International Journal of Medical Sciences, vol. 13, no. 11, pp. 853857, 2016.

[8] Z. A. Al-Safi and A. J. Polotsky, "Obesity and Menopause," Best Practice \& Research Clinical Obstetrics \& Gynaecology, vol. 29, no. 4, pp. 548-553, 2015.

[9] R. C. Thurston and H. Joffe, "Vasomotor Symptoms and Menopause: Findings from the Study of Women's Health across the Nation," Obstetrics and Gynecology Clinics of North America, vol. 38, no. 3, pp. 489-501, 2011.

[10] A. N. Shuid, L. L. Ping, N. Muhammad, N. Mohamed, and I. N. Soelaiman, "The effects of Labisia pumila var. alata on bone 
markers and bone calcium in a rat model of post-menopausal osteoporosis," Journal of Ethnopharmacology, vol. 133, no. 2, pp. 538-542, 2011.

[11] S. Davison and S. R. Davis, "Hormone replacement therapy: current controversies," Clinical Endocrinology, vol. 58, no. 3, pp. 249-261, 2003.

[12] J. C. Stevenson, "Justification for the use of HRT in the longterm prevention of osteoporosis," Maturitas, vol. 51, no. 2, pp. 113-126, 2005.

[13] Z. Zhang, T.-N. Lam, and Z. Zuo, "Radix puerariae: an overview of its chemistry, pharmacology, pharmacokinetics, and clinical use," Clinical Pharmacology and Therapeutics, vol. 53, no. 8, pp. 787-811, 2013.

[14] H. W. Jung, A. N. Kang, S. Y. Kang, Y.-K. Park, and M. Y. Song, "The root extract of pueraria lobata and its main compound, puerarin, prevent obesity by increasing the energy metabolism in skeletal muscle," Nutrients, vol. 9, no. 1, 2017.

[15] S.-Y. Yuan, T. Sheng, L.-Q. Liu et al., "Puerarin prevents bone loss in ovariectomized mice and inhibits osteoclast formation in vitro," Chinese Journal of Natural Medicines, vol. 14, no. 4, pp. 265-269, 2016.

[16] J. K. Prasain, K. Jones, M. Kirk et al., "Profiling and quantification of isoflavonoids in kudzu dietary supplements by highperformance liquid chromatography and electrospray ionization tandem mass spectrometry," Journal of Agricultural and Food Chemistry, vol. 51, no. 15, pp. 4213-4218, 2003.

[17] O. H. Franco, R. Chowdhury, J. Troup et al., "Use of plant-based therapies and menopausal symptoms: A systematic review and meta-analysis," Journal of the American Medical Association, vol. 315, no. 23, pp. 2554-2563, 2016.

[18] E. Piatczak, L. Kuzma, W. Porada, B. Olas, and H. Wysokinska, "Evaluation of antioxidant properties of methanolic extracts from leaves and roots of rehmannia glutinosa libosch. In human blood," Acta Poloniae Pharmaceutica, vol. 72, no. 4, pp. 777-783, 2015.

[19] H. M. Ok, M. R. Gebreamanuel, S. A. Oh, H. Jeon, W. J. Lee, and O. Kwon, "A root-based combination supplement containing pueraria lobata and rehmannia glutinosa and exercise preserve bone mass in ovariectomized rats fed a high-fat diet," Calcified Tissue International, vol. 97, no. 6, pp. 624-633, 2015.

[20] H. J. Kim, H. M. Yoon, O. Kwon, and W. J. Lee, “The effect of pueraria lobata/rehmannia glutinosa and exercise on fatty acid transporters expression in ovariectomized rats skeletal muscles," Journal of Exercise Nutrition \& Biochemistry, vol. 20, no. 3, pp. 32-38, 2016.

[21] S. A. Oh, H. M. Ok, H. J. Kim, W. J. Lee, and O. Kwon, "Effects of a Pueraria lobata-root based combination supplement containing Rehmannia glutinosa and aerobic exercise on improvement of metabolic dysfunctions in ovariectomized rats," Journal of Nutrition and Health, vol. 48, no. 2, pp. 133-139, 2015.

[22] N. Kanaya and S. Chen, "Conjugated linoleic acid reduces body weight gain in ovariectomized female C57BL/6J mice," Nutrition Research, vol. 30, no. 10, pp. 714-721, 2010.

[23] J. Wu, X. Wang, H. Chiba et al., "Combined intervention of soy isoflavone and moderate exercise prevents body fat elevation and bone loss in ovariectomized mice," Metabolism - Clinical and Experimental, vol. 53, no. 7, pp. 942-948, 2004.

[24] W. Zhang, T. Fujikawa, K. Mizuno et al., "Eucommia leaf extract (ELE) prevents OVX-induced osteoporosis and obesity in rats," American Journal of Chinese Medicine, vol. 40, no. 4, pp. 735752, 2012
[25] A. T. Ali, W. E. Hochfeld, R. Myburgh, and M. S. Pepper, "Adipocyte and adipogenesis," European Journal of Cell Biology, vol. 92, no. 6-7, pp. 229-236, 2013.

[26] M. Luna-Luna, A. Medina-Urrutia, G. Vargas-Alarcón, F. Coss-Rovirosa, J. Vargas-Barrón, and Ó. Pérez-Méndez, “Adipose tissue in metabolic syndrome: onset and progression of atherosclerosis," Archives of Medical Research, vol. 46, no. 5, pp. 392-407, 2015.

[27] U. J. Jung and M. S. Choi, "Obesity and its metabolic complications: the role of adipokines and the relationship between obesity, inflammation, insulin resistance, dyslipidemia and nonalcoholic fatty liver disease," International Journal of Molecular Sciences, vol. 15, no. 4, pp. 6184-6223, 2014.

[28] T. K. T. Lam, A. Carpentier, G. F. Lewis, G. van de Werve, I. G. Fantus, and A. Giacca, "Mechanisms of the free fatty acid-induced increase in hepatic glucose production," American Journal of Physiology-Renal Physiology, vol. 284, no. 5, pp. E863E873, 2003.

[29] N. H. Rogers, J. W. Perfield, K. J. Strissel, M. S. Obin, and A. S. Greenberg, "Reduced energy expenditure and increased inflammation are early events in the development of ovariectomy-induced obesity," Endocrinology, vol. 150, no. 5, pp. 2161-2168, 2009.

[30] T. Andersson, K. Simonyte, R. Andrew et al., “Tissue-specific increases in $11 \beta$-hydroxysteroid dehydrogenase Type 1 in normal weight postmenopausal women," PLoS ONE, vol. 4, no. 12, Article ID e8475, 2009.

[31] C.-C. Liao, Y.-S. Chiu, W.-C. Chiu et al., "Proteomics analysis to identify and characterize the molecular signatures of hepatic steatosis in ovariectomized rats as a model of postmenopausal status," Nutrients, vol. 7, no. 10, article no. A39, pp. 8752-8766, 2015.

[32] Y. Kamada, S. Kiso, Y. Yoshida et al., "Estrogen deficiency worsens steatohepatitis in mice fed high-fat and high-cholesterol diet," American Journal of Physiology-Gastrointestinal and Liver Physiology, vol. 301, no. 6, pp. G1031-G1043, 2011.

[33] A. Paquette, N. A. Chapados, R. Bergeron, and J.-M. Lavoie, "Fatty acid oxidation is decreased in the liver of ovariectomized rats," Hormone and Metabolic Research, vol. 41, no. 7, pp. 511-515, 2009.

[34] I.-H. Kim and T.-J. Nam, "Enzyme-Treated Ecklonia cava extract inhibits adipogenesis through the downregulation of $\mathrm{C} / \mathrm{EBP} \alpha$ in 3T3-L1 adipocytes," International Journal of Molecular Medicine, vol. 39, no. 3, pp. 636-644, 2017.

[35] M. M. Domingos, M. F. C. Rodrigues, U. S. Stotzer et al., "Resistance training restores the gene expression of molecules related to fat oxidation and lipogenesis in the liver of ovariectomized rats," European Journal of Applied Physiology, vol. 112, no. 4, pp. 1437-1444, 2012.

[36] S. Luci, B. Giemsa, H. Kluge, and K. Eder, "Clofibrate causes an upregulation of PPAR- $\alpha$ target genes but does not alter expression of SREBP target genes in liver and adipose tissue of pigs," American Journal of Physiology-Regulatory, Integrative and Comparative Physiology, vol. 293, no. 1, pp. R70-R77, 2007.

[37] V. Barquissau, R. A. Ghandour, G. Ailhaud et al., "Control of adipogenesis by oxylipins, GPCRs and PPARs," Biochimie, vol. 136, pp. 3-11, 2017.

[38] G. M. Thompson, D. Trainor, C. Biswas, C. LaCerte, J. P. Berger, and L. J. Kelly, "A high-capacity assay for PPAR $\gamma$ ligand regulation of endogenous aP2 expression in 3T3-L1 cells," Analytical Biochemistry, vol. 330, no. 1, pp. 21-28, 2004. 
[39] J. B. Boord, K. Maeda, L. Makowski et al., "Adipocyte fatty acidbinding protein, aP2, alters late atherosclerotic lesion formation in severe hypercholesterolemia," Arteriosclerosis, Thrombosis, and Vascular Biology, vol. 22, no. 10, pp. 1686-1691, 2002.

[40] V. I. Alexaki and T. Chavakis, "The role of innate immunity in the regulation of brown and beige adipogenesis," Reviews in Endocrine and Metabolic Disorders, vol. 17, no. 1, pp. 41-49, 2016.

[41] F. Mauvais-Jarvis, D. J. Clegg, and A. L. Hevener, "The role of estrogens in control of energy balance and glucose homeostasis," Endocrine Reviews, vol. 34, no. 3, pp. 309-338, 2013.

[42] N. M. Al-Daghri, I. Aziz, S. Yakout et al., "Inflammation as a contributing factor among postmenopausal Saudi women with osteoporosis," Medicine, vol. 96, no. 4, p. e5780, 2017.

[43] A. Macciò and C. Madeddu, "Obesity, inflammation, and postmenopausal breast cancer: therapeutic implications," The Scientific World Journal, vol. 11, pp. 2020-2036, 2011.

[44] M. F. Rodrigues, F. C. Ferreira, N. S. Silva-Magosso et al., "Effects of resistance training and estrogen replacement on adipose tissue inflammation in ovariectomized rats," Applied Physiology, Nutrition, and Metabolism, vol. 42, no. 6, pp. 605612, 2017.

[45] O. A. Alkhamees, A. S. Al-Roujayee, H. M. Abuohashish, and M. M. Ahmed, "Anti-osteoporotic effects of an antidepressant tianeptine on ovariectomized rats," Biomedicine \& Pharmacotherapy, vol. 87, pp. 575-582, 2017. 


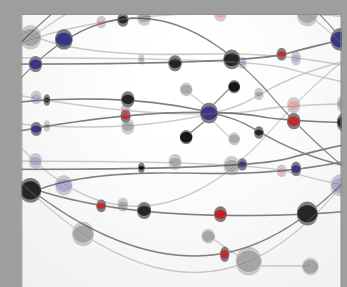

The Scientific World Journal
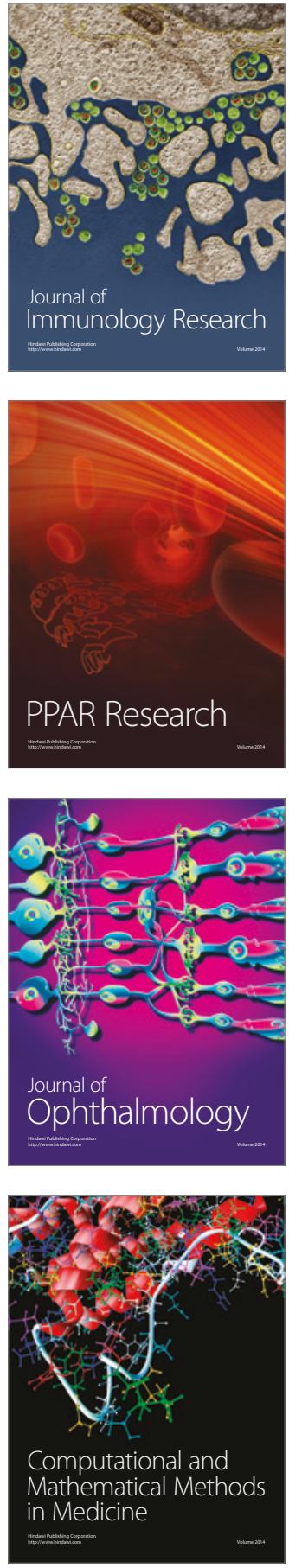

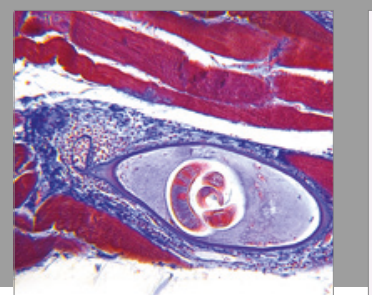

Gastroenterology Research and Practice
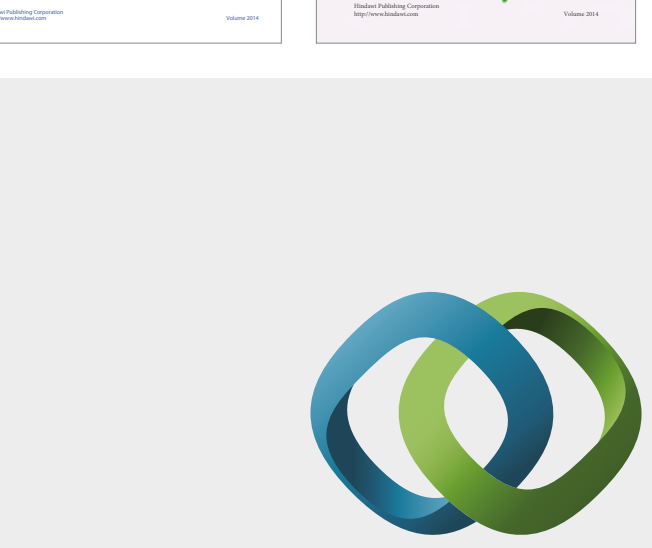

\section{Hindawi}

Submit your manuscripts at

https://www.hindawi.com
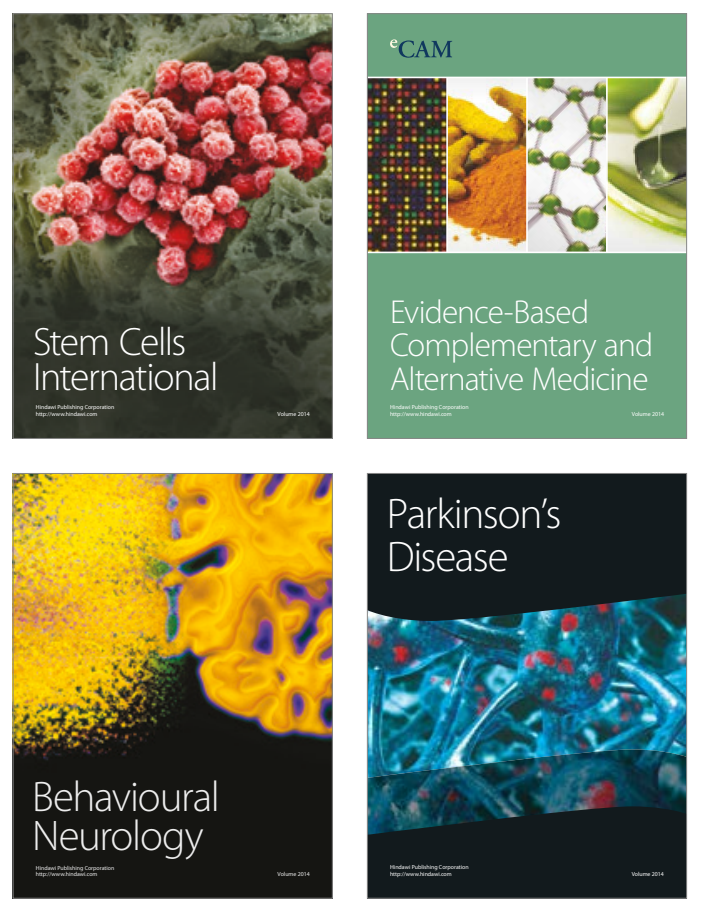
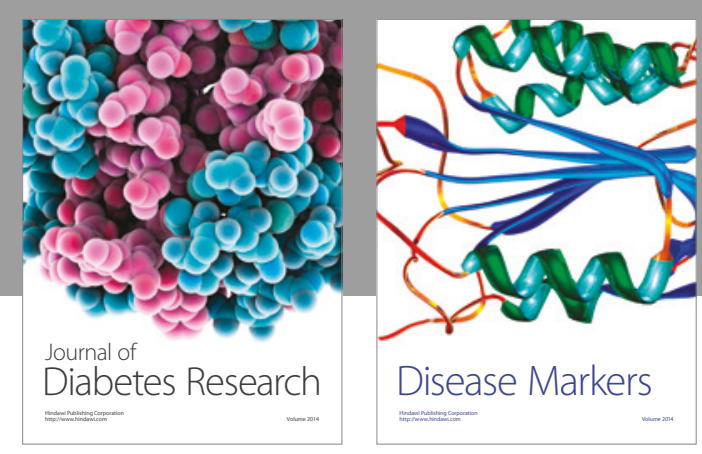

Disease Markers
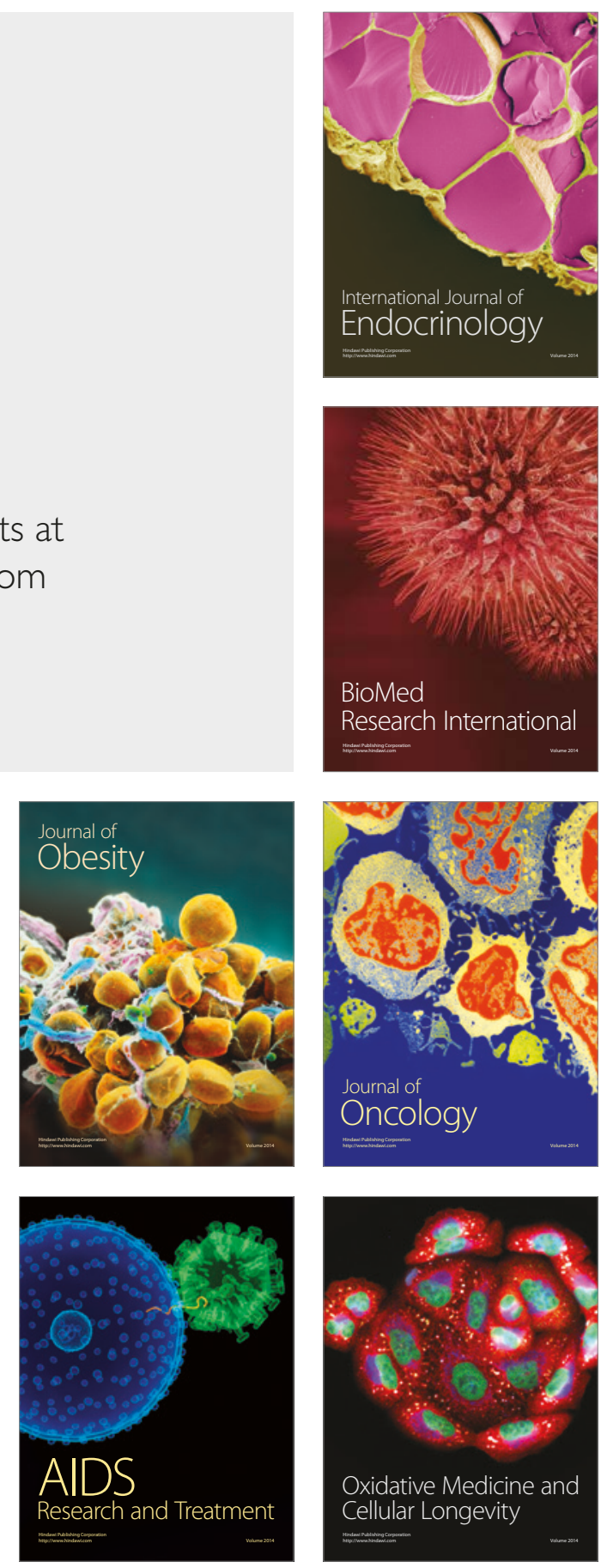